\title{
Maternal health in fifty years of Tanzania independence: Challenges and opportunities of reducing maternal mortality
}

\author{
ANGELA E.SHIJA, JUDITH MSOVELA and LEONARD E.G. MBOERA, \\ National Institute for Medical Research, P.O. Box 9653, Dar es Salaam, Tanzania
}

\begin{abstract}
High rate of maternal death is one of the major public health concerns in Tanzania. Most of maternal deaths are caused by factors attributed to pregnancy, childbirth and poor quality of health services. More than $80 \%$ of maternal deaths can be prevented if pregnant women access essential maternity care and assured of skilled attendance at childbirth as well as emergency obstetric care. The objective of this review was to analyse maternal mortality situation in Tanzania during the past 50 years and to identify efforts, challenges and opportunities of reducing it. This paper was written through desk review of key policy documents, technical reports, publications and available internet-based literature. From 1961 to 1990 maternal mortality ratio in Tanzania had been on a downward trend from 453 to 200 per 100,000 live births. However, from 1990's there been an increasing trend to 578 per 100,000 live births. Current statistics indicate that maternal mortality ratio has dropped slightly in 2010 to 454 per 100,000 live births. Despite a high coverage (96\%) in pregnant women who attend at least one antenatal clinic, only half of the women (51\%) have access to skilled delivery. Coverage of emergence obstetric services is $64.5 \%$ and utilization of modern family planning method is $27 \%$. Only about $13 \%$ of home deliveries access post natal check-up. Despite a number of efforts maternal mortality is still unacceptably high. Some of the efforts done to reduce maternal mortality in Tanzania included the following initiatives: reproductive and child survival; increased skilled delivery; maternal death audit; coordination and integration of different programs including maternal and child health services, family planning, malaria interventions, expanded program on immunization and adolescent health and nutrition programmes. These initiatives are however challenged by inadequate access to maternal health care services. In order to considerably reduce maternal deaths some of recommended strategies include: (i) strengthening the health system to provide skilled attendance during child birth; (ii) upgrading rural health centres to provide emergency obstetric services; (iii) providing adolescent and male friendly family planning services; (iv) strengthening public-private partnership to ensure continuum of care; ( $v$ ) supporting operational research to answer the immediate concerns of the health system; and (vi) strengthening community participation and women empowerment to take role of their own health and the family at large. In conclusion, maternal mortality ratio in Tanzania is unacceptably high and still very far from reaching the millennium development goals. Maternal health care services should focus on ensuring there is continuum of care through strengthening the health system; provision of good quality of health care in a well organized referral health system and operation research to support programme implementation.
\end{abstract}

Keywords: maternal, health, mortality, obstetric care, Tanzania

\section{Background}

Despite a number of global and national efforts to improve women's health, death of women during child birth remains an unresolved challenge in many developing countries, including Tanzania. Some estimates indicate that at least half million women die from pregnancy related causes (WHO/UNICEF/UNFPA/The World Bank, 2007). The estimates further show that $99 \%$ of these deaths occurs in developing countries, especially in sub-Saharan Africa and there is slower pace in reducing maternal mortality compared to other regions of the world from 1990 to 2005. While the overall the global decline in maternal mortality ratio between 1990 and 2005 was 5.4\%, the annual decline was less than $1 \%$. The situation was noted to be worse in sub-Saharan Africa where the decline has been $0.1 \%$. It is worth noting that in Sub-Saharan Africa the number of maternal deaths increased between 1990 and 2005, this has been driven by the increasing number of births and a negligible decline in the maternal mortality ratio.

Most of maternal deaths are caused by factors attributed to pregnancy, childbirth and poor quality of health services. About $60 \%$ of maternal deaths occur during labour, delivery and immediate postpartum period. Fifty percent of these deaths occur within the first 24 hours of delivery (Koblinky, 2003; Campbell et al., 2006). Comparatively, a woman in East Africa has 1 in 12 
risk of dying due to pregnancy as compared to 1 in 4,000 in northern Europe (FHI, 2007). Most complications cannot be predicted; therefore timely diagnosis with skilled personnel is important to avoid introducing harm (Campbell et al., 2006).

Maternal mortalities are caused by different factors which can be categorized as direct, indirect and underlying causes. The major direct causes include obstetric haemorrhage, obstructed labour, pregnancy induced hypertension, sepsis and abortion complications (Urassa et al., 1995; AbouZahr, 1995; WHO, 2010). The direct causes are related to obstetric complications and contribute to three quarters of maternal deaths (Starr, 1997). Poor access to reproductive service increases risks of getting unwanted pregnancies. Teenagers in Africa account for about $20 \%$ of maternal deaths and most are due to unsafe abortion (Rogo et al., 2006). Since abortion is legally restricted in these countries including Tanzania victims resort to street abortions (Rogo et al., 2006). .

Indirect causes account for $20-25 \%$ of maternal deaths and they include malaria, HIV/AIDS, hepatitis, diabetes mellitus and heart diseases (WHO, 2005). Malaria in pregnancy predisposes women to a number of complications including anaemia, which places them at higher risk of maternal mortality from haemorrhage, and contributes to spontaneous abortions and low birth weight babies (WHO, 2005). Maternal anaemia affects about half of all pregnant women and adolescents (WHO, 2007). Anaemia occurs in 16.0-26.0\% of antenatal care attendees in Tanzania (Massawe et al., 1999). Other causes of maternal death include poor access to reproductive services, weak health system, low socio-economic and cultural factors (Urassa et al., 2006; Rogo et al., 2006).

Despite the current increasing indirect causes of maternal death as a result of HIV/AIDS pandemic, still the majority of deaths are due to direct obstetric causes. Maternal death due to the direct causes can be prevented if timely access to appropriate emergency obstetric care (EmOC) is availed. But maternal deaths only tell part of the story. For instance, it is acknowledged that for every woman who dies as a result of pregnancy-related causes, between 20 and 30 more women will develop short- and long-term disabilities, such as obstetric fistula, a ruptured uterus, or pelvic inflammatory disease (Waldijk, 1994). Such morbidities impacts on the active labourforce necessary for eradication of poverty in developing countries, not only of the family but also the community who have to care for the children and/or the disabled women at the expense of economic activities necessary for their livelihoods.

Different initiatives have been put forward by different international forums which required individual nation's response towards minimizing maternal death rates. Key initiatives included: the UN declaration in 1975 of a decade (1976-1985) aiming at raising international attention on the health, rights, and development priorities of women (FHI, 2007) and the AlmaAta declaration of 1978 on primary health which calls for all nations to protect and promote the health of all the people by providing maternal and child health care (WHO, 1978). In 1987, a global initiative of Safe Motherhood was inaugurated in Nairobi, Kenya (FHI, 2007). However, maternal mortality component was not recognized as a public health concern and was overlooked component of maternal-child health programmes. World Summit for Children conference was held in 1989 and identified Maternal mortality as critical to the health and survival of children, and the summit called for a reduction of maternal mortality (AbouZahr, 2003). The International Conference on Population and Development (ICPD) of 1994 aimed at securing the reproductive health and rights of men and women of all ages through comprehensive approach to reproductive health. In 2000, the UN General Assembly came up with eight Millennium Development Goals with the fifth goal calling for an improvement in maternal health and a reduction in maternal mortality by three quarter (75\% ) from 1990 to 2015 (UN, 2011). Expanded global partnership for maternal health in 2005 brought together three existing global health coalitions on maternal, newborn, and child health which aimed at strengthening global advocacy and leadership in an effort to raise the profile and visibility of maternal, newborn, and child health; develop and promote a continuum of care for mothers and children; and coordinate country-level support and action (Sines et al., 2006; FCl, 2007; FHI, 2007). 
There are a number of interventions which have proved to reduce maternal mortality. These include strengthening of health system; universal accessibility to emergency obstetric services; comprehensive ANC services and availability of safe blood for obstetric services. Other interventions include provision of reproductive health and family planning services and provision of safe abortion services; women empowerment and male involvement in reproductive issues and public private partnership (Wagstaf \& Claeson, 2004; Rogo et al., 2006; Sines et al., 2006). Despite both international and national responses to improve women's health, maternal death during child birth has remained an unresolved challenge in Tanzania. Among the eight millennium development goals, the fifth goal aimed to reduce maternal mortality rate (MMR) by three quarters (75\%) from 1990 to 2015 (UN, 2011) and ensure universal access to reproductive health services. Globally, efforts to reduce death among women and children have been less successful than in any other areas on human development-with the result that bearing a child remains among the most serious health risks for women (UNICEF, 2009). The objective of this review was to identify efforts and challenges facing reduction of maternal mortality during the 50 years of Tanzania independence (1961-2011). This review covers maternal mortality situation in Tanzania; historical background on Tanzanian response to the global efforts; challenges and opportunities towards reduction of maternal death and the way forward. This paper was written through desktop review of government policy documents, guidelines, journal publications, technical reports and internet search.

\section{Maternal mortality situation in Tanzania}

From independence in 1961 to 1990 maternal mortality had been on downward trend (Table 1). In 1990 s the trend reversed to an upward direction. The Tanzania Demographic and Health Surveys (TDHS) of 1999 and 2005 estimated the maternal mortality ratio to be 528 and 578 per 100,000 live births, respectively (TDHS, 1999, 2005). However, during the same period, international organizations estimate was 950 per 100,000 live birth with a range of 620-1300 per 100,000 live birth in the year 2005 (WHO/UNICEF/UNFPA/The World Bank, 2007). This gives the total number of maternal deaths in the country to be between 8,000 and 13,000 annually. Factors contributing to this trend could be partly due to the economic crisis during that particular period, which led to the weakening of the health system. To cope with that situation the government introduced cost sharing system. In addition the government froze employment of health workers. For instance, human resource declined from 67,000 in 1994 to 49,000 in 2001/02 and this affected staff ratio across main cadres including clinicians and nurses who provide most of maternal health care services. According to Ministry of Health staff ratio in 1999 available health professionals was $32.1 \%$ of the requirement. This was equivalent to $67.9 \%$ shortage (MoHSW, 2007). Generally the health system weakened and hence the accessibility and quality of maternal health services delivery worsened.

Table 1: The trend of maternal mortality in Tanzania, 1961-2010

\begin{tabular}{ll}
\hline Year & Maternal mortality per 100,000 births \\
\hline 1961 & 453 \\
1967 & 351 \\
1972 & 252 \\
1985 & 167 \\
1986 & 197 \\
1987 & 190 \\
1990 & 190 \\
1991 & 215 \\
1996 & 529 \\
$2004 / 05$ & 578 \\
$\mathbf{2 0 1 0}$ & 454 \\
\hline Source (Mandara et al., 1991; TDHS, 2005, 2010)
\end{tabular}


Recent reports show that maternal mortality ratio (MMR) has been reduced from 578 in 2004/05 to 454 in 2010 (TDHS, 2010). However, this ratio is still unacceptably high and puts Tanzania among the countries with highest maternal mortality in the world. Furthermore ,the current MMR is far behind National Strategy for Growth and Reduction of Poverty (NSGRP) target of 265 and MDG target of 133 by 2015 (MOHSW, 2008b; URT,2010). Taking into consideration that the current status has taken around ten years, the question remains whether there is any possibility of attaining the targeted MDG goal in the remaining time.

\section{Tanzania efforts in response to global initiatives to reduce maternal mortality}

\section{Previous efforts from 1970-2000}

In response to international efforts, different policies, strategies, and interventions have been implemented in Tanzania since independence. The strategies and interventions are geared to address the core factors contributing to maternal death. Since independence various efforts have been taken to address maternal death issues and ensure provision of maternal health care at all levels. The National Executive Committee declared its support for the Family Planning Association (UMATI) in 1974. UMATI, established in 1959, plays three main roles; motivates, educates and inform the general public on the need of the child spacing; trains service providers on benefits of child spacing and family planning in both government and nongovernment facilities. In addition UMATI procures and distribute contraceptives to women. In the same year the Government through the Ministry of Health integrated child spacing advice and services into Maternal and Child Health Services (MCH) in all health facilities in the country. In 1984 Tanzania started to undertake maternal death reviews at different levels of health facilities (Commonwealth Secretariat, 2008).

Tanzania was the first country in Sub-Saharan Africa to endorse and adopt the Safe Motherhood Initiative strategy in 1989 (FHI 2007). The first national population policy aimed at strengthening family planning by increasing the use of modern family planning among women of reproductive age was developed in 1992 (URT 2007). Later, the country developed a Strategy for Reproductive Health and Child Survival 1997-2001 which aimed at improving the health of women, children, and adolescents. With regard to maternal health care, the strategy aimed to reduce maternal mortality by $50 \%$ by the year 2001 through improving the nutritional and socioeconomic status of women; strengthening post-abortion and antenatal care; reviving postnatal care; increase human resource capacity for managing maternal care; strengthening management of obstetrical problems in health facilities; and enhancing efficiency of the referral system.

\section{Efforts from 2000 to 2010}

National Package of Essential Reproductive and Child Health Interventions were developed in the 2000. The strategy was focusing on improving quality of life of women and adolescent and children. The package includes provision of antennal care, care during child birth, Emergence Obstetric care (EmOC) and post-partum care $(\mathrm{MoH}, 2000)$. The National Policy Guidelines for Reproductive and Child Health Services was developed in 2003 ( $\mathrm{MoH}, 2003)$ followed by Reproductive and Child Health Strategy, 2005-2010 in 2004. The strategy is focusing at improving the quality of reproductive and child health services that are accessible, affordable, sustainable, and which are provided through an efficient and effective support system. The key priority areas identified are focused antenatal care, skilled care during childbirth, care for obstetric emergencies, postpartum care, post-abortion care, family planning, and prevention of harmful practices $(\mathrm{MoH}, 2004)$. In order to improve adolescent health and harmonizing various stakeholders efforts the National Policy on Reproductive and Child Health (2003), the National Adolescent Health and Development Strategy (2004-2008) and Strategy for Adolescent Friendly Reproductive health Services (2005) were developed by the government (MoHSW, 2006). 
Other policy guidelines were developed in 2005 to ensure availability of sufficient skilled health workers and delivery of quality health care delivery. These included Guidelines for Reforming Hospitals at Regional and District Levels, National Tracer Standards, Indicators for Quality Improvement in Health Care and Proposed Staffing levels for Health Facilities and Training Institutions (MoH, 2005). In the same year the first National Strategy for Growth and Reduction of Poverty (NSGPR) 2005-2010 (URT, 2005) document was developed in line with the Tanzania Vision 2025 (Tanzania Development Vision 2025). The NSGPR Cluster II aimed to improve quality of life and social welfare by providing two indicators to monitor progress of MDG-5 which includes reduction of maternal mortality from 529 to 265 per 100,000 and increase coverage of birth attended by trained personnel from $50 \%$ to $80 \%$ by 2010 (URT, 2005). The NSGPR was to be achieved by implementation of strategic plan for health sector 2003-2008. However, this goal was not achieved as indicated in the recent Tanzania Demographic and Health Survey of 2010 (TDHS, 2010). In 2006 the National Population policy (URT, 2006) was revised to promote and expand comprehensive quality reproductive services to cater for the need of adolescents, youths and elderly together with addressing the eradication of harmful traditional practice such as female genital mutilation and encourage male participation in reproductive health services. In 2006, the government developed the National Road Map Strategic Plan to Accelerate the Reduction of Maternal and Newborn Mortality (2006-2010). In 2007 Tanzania Partnership for Maternal Newborn and Child Health Work Plan, 2007-2008 was launched to re-focus the strategies for reducing the persistently high maternal and child mortality rates through adopting One Plan and setting target for improved maternal and child health (MoHSW, 2008a).

Primary Health Service Development Programme2007-2017, was launched in 2007 (MoHSW, 2007) with the main objective of providing health care to all Tanzanians by 2012 by focusing on the following areas: strengthening the health system, rehabilitation of health facilities, human resources development, strengthening the referral system, equipment and supplies. Also to ensure access to emergency obstetric care (EmOC) services by providing ambulances, motorcycle especially to rural health facilities (MOHSW, 2007). On the same year the Ministry of Health developed a draft of Maternal and Peri-natal Death Audit Guidelines.

In 2008, the Health Sector Support Programme III (2008-2012) (MoHSW, 2007) was launched. This is cross cutting strategic plan across the health sector to guide development of council and hospital strategic plans and annual implementation plan. In the same year The National Road Map Strategic Plan to Accelerate Reduction of Maternal, Newborn and Child Health in Tanzania 2008-2015 (One Plan) was developed. The plan aims at improving coordination of interventions and delivery of services across the continuum of care. The programmes that were integrated in Maternal and Child Health services include Safe motherhood; Family Planning; Prevention of Mother to Child Transmission; Malaria; Expanded Programme on Immunisation; Adolescent Health and Nutrition (MoHSW, 2008a). In addition, other policy guidelines were introduced during the same year. These were the Human Resource for Health Strategic Plan, 2008-2013, Draft National Supervision Guidelines for Quality Health Care Services, Focused Antenatal Care and Natal and Post Natal Care Guidelines. Overall, maternal and child health is a single programme that is managed by a number of policy guidelines than any other programme in Tanzania.

\section{Other initiative to support maternal health in Tanzania}

The government established National Health Insurance Fund (NHIF) in 2001 and Community Health Fund 1996, which helped to improve access to health care to members and their family, hence even the poor can access health care of high facility without selling their assets to get money for treatment (Mtei et al., 2007). The Ministry of Health established Reproductive and Child Health section which will coordinate all efforts towards provision of maternal health care. The National Blood Transfusion Programme was established in 2004 to ensure safe blood is available for emergencies including obstetric cases. Currently, the progamme has eight zone 
offices that save the whole country. The Ministry of Health and Social Welfare in collaboration with Ifakara Health institute have established a 3-month course to train Assistant Medical Officers in carrying out emergency obstetric surgery; and nurses on how to provide safe anaesthesia in rural health centres. This was the first course of its type to be introduced in sub-Saharan Africa (URT, 2009). Graduates from this course have started to support nine rural health centres in Morogoro, Kigoma and Coast regions in providing caesarean sections which have increased deliveries to more than $50 \%$ in the upgraded health centre (WLF, 2011).

Tanzania National Voucher Scheme which started in 2004 has helped to increase access and utilization of insecticide treated mosquito nets (ITN) to pregnant women and children for malaria prevention. Since 2008, the government launched a programme to distribute ITN to under fives through the US President Malaria Initiative. In addition, Tanzania is providing free maternal healthcare during antenatal and delivery as strategy to increase access to skilled birth attendance and emergency obstetric care for reducing maternal death. In 2007 misoprostol drug was registered in Tanzania for prevention and treatment of postpartum haemorrhage in hard to reach population (VSI-IHI, 2011). Since 2009, the government has provided tri-cycle ambulances in rural areas as a means of improving attendance to obstetric emergence services. In year 2009/10 a total of 370 tri-cycle ambulances were purchased and distributed to health centres and dispensaries (URT, 2009).

\section{Maternal health care services in Tanzania and their coverage}

It is estimated that over $80 \%$ of the Tanzanian population live within $5 \mathrm{~km}$ from the health facility. However, in spite of this relatively good coverage of health facilities, not all components of essential maternal services are provided (MoHSW, 2007). Despite a high attendance (96\%) of pregnant women to antenatal clinic (ANC), deliveries assisted by skilled attendants are still low ( mean=51\%; urban =83\%; rural 42\%) which is below NSGRP target of $80 \%$ skilled delivery (URT, 2005). Pregnancy complications increases with HIV/AIDS and malaria therefore, pregnant women attending ANC are entitled to receive intermittent preventive treatment for malaria and ferrous sulphate for anaemia prevention. Screening of HIV and syphilis and prevention of mother to child transmission of HIV (PMTCT) services are provided to expectant mother free of charge. Current statistics indicate that in $201057 \%$ pregnant women slept under ITN, 66\% received single dose of IPT, 26\% received two doses of IPT and HIV testing among women was 30\% (TDHS, 2010).

Emergency obstetric care $(\mathrm{EmOC})$ services are crucial in addressing complicated pregnancies. However, the lack of functioning blood banks at most health facilities in Tanzania is correlated with the low rate of caesarean sections. According to TDHS (2005), about 3\% of babies born are delivered by caesarean sections, which is below the recommended 5-15\% caesarean deliveries as a proportion of all births in the population (UNICEF, 2009). Health facilities providing comprehensive emergency obstetric care were $64.5 \%$, while only $5.5 \%$ of the health centres were providing Basic Emergency Obstetric Care which is below NSGRP (2005) goals of increase coverage of CEmOC at hospital level from $64 \%$ to $100 \%$ and basic EmOC at health centres and dispensaries from $5 \%$ to $70 \%$ by 2010 .

The current use of modern family planning among married women of 15-49 years stands at $27 \%$ as compared to unmarried women of $45 \%$ (TDHS, 2010). The current proportion of women who use family planning is far behind the NSGRP target of 60\% (URT, 2005). Adolescent friendly reproductive health services need to be addressed as young people under the age of 24 years make up nearly two-thirds of the Tanzanian population and they have special concerns with regards to maternal and neonatal health.

In a recent study covering 15 districts of Tanzania, only $11.6 \%$ and $3.9 \%$ of all the facilities had all elements of reproductive and delivery services, respectively. Staffing for reproductive health services was poor $(<50 \%)$ across facilities in all the districts. In terms of equipment and supply, all facilities in the 15 districts were doing very well scoring $\geq 90 \%$. However, all elements of delivery services were not available in Kigoma, Meatu, Rungwe, Songea, Kaskazini A and Wete 
districts. The proportion of trained staff for supporting delivery in the districts was quite low (URT, 2011).

Most maternal death occurs in the first 24 hours to 7 days after delivery which is the period where haemorrhage and sepsis can happen. Postnatal care is a key for continuum of care from home to health facility for both maternal and baby health since women can access family planning counselling, management of anaemia, referral for bleeding and infection complication and baby check-up as well. However, postnatal care in Tanzania is poorly accessed especially to women who deliver at home (TDHS, 2004/2005). As reported by MoHSW (2009), health facilities offering post natal care services are only $60 \%$ of $82 \%$ facilities which offers antennal care. The report also indicated overall poor attendance to postnatal check-up in the country of less than $30 \%$ since majority (71\%) do attend after four weeks due to economic barriers to access health care services and cultural taboos around leaving the home during period of seclusion (Table 2).

Table 1 : Timing of first postnatal visit

\begin{tabular}{lll}
\hline Timing of first postnatal visit & Frequency & Percent \\
\hline Within one week & 9 & $6 \%$ \\
Between 1-4 weeks & 36 & $23 \%$ \\
After 4 weeks & 112 & $71 \%$ \\
Total & 157 & $100 \%$ \\
\hline Source: Situation Analysis of newborn health in Tanzania Report, 2009 (MoHSW, 2009)
\end{tabular}

Furthermore, the referral system has serious challenges including limited number of ambulances; unreliable logistics and communication system; and low community based facilitated referral system. Weakness in the health system has direct impact on the delivery of maternal and newborn services i.e. shortage of skilled providers in most of health units, lack or inadequate supplies equipments, poor infrastructures, inadequate and poor referral system.

Table 3: Indicator targets of various national commitments

\begin{tabular}{|c|c|c|c|c|c|}
\hline Indicators & NSGPR Target & $\begin{array}{l}\text { PHSDP } \\
\text { Target }\end{array}$ & $\begin{array}{l}\text { National } \\
\text { Roadmap }\end{array}$ & MDG target & $\begin{array}{l}\text { Current } \\
\text { status* }\end{array}$ \\
\hline $\begin{array}{l}\text { Maternal } \\
\text { Mortality Ratio }\end{array}$ & $\begin{array}{ll}\text { From } 529 & \text { to } \\
265 \text { in } 2010 & \end{array}$ & $\begin{array}{l}\text { From } 578 \text { to } \\
220 \text { by } 2012\end{array}$ & $\begin{array}{l}\text { From } 578 \text { to } \\
193 \text { by } 2015\end{array}$ & $\begin{array}{l}\text { From } 529 \text { to } 133 \\
\text { by } 2015\end{array}$ & 578 \\
\hline $\begin{array}{l}\text { Births attended by } \\
\text { trained personnel }\end{array}$ & $\begin{array}{l}\text { From } 50 \% \text { to } \\
80 \% \text { in } 2010\end{array}$ & $\begin{array}{l}46 \% \text { in } 2004 \text { to } \\
80 \% \text { by } 2012\end{array}$ & $\begin{array}{l}\text { From } 46 \% \text { to } \\
80 \% \text { by } 2015\end{array}$ & & $51 \%$ \\
\hline $\begin{array}{l}\text { ANC attendance } \\
\text { at least } 4 \text { visits }\end{array}$ & - & - & $\begin{array}{l}\text { From } 64 \% \text { to } \\
90 \% \text { by } 2015\end{array}$ & - & $43 \%$ \\
\hline $\begin{array}{l}\text { Modern } \\
\text { contraceptive } \\
\text { prevalence rate }\end{array}$ & & & $\begin{array}{l}\text { From } 20 \% \text { to } \\
60 \% \text { by } 2015\end{array}$ & $\begin{array}{l}\text { Universal access } \\
\text { to family } \\
\text { planning by } 2015\end{array}$ & $27 \%$ \\
\hline
\end{tabular}

Key: NSGPR = National Strategy for Growth and Poverty Reduction; PHSDP= Primary Health Services Development Programme, 2007-2017; *TDHS (2010)

\section{Challenges in Reduction of Maternal Death in Tanzania}

Despite various efforts done in the country by the government and development partners, maternal mortality ratio in Tanzania has remained very high in the past 10 years and is beyond halfway to reach the MDG target of 133. A number of challenges still prevail as follows. Accessibility to maternal health care services is still inadequate particularly in rural and underserved areas. Available reports show that only 51\% of pregnant women are attended by skilled providers during delivery. Furthermore emergency obstetric care (EMOC) service is available in $64.5 \%$ of health facilities. Poor utilization of Post-natal check-up of less than $30 \%$ increases the risk of maternal death since most of these deaths are happening during the first 24 hours to seven days. The shortage of EMOC services together with other factors such as 
inadequate infrastructure, poor communication and transport between health facilities and district hospital, inadequate number of skilled personnel and irregular supplies of essential drugs and equipment make the accessibility of this important intervention not possible to a greater number of women.

Despite a high knowledge of family planning among women of reproductive age, only $27 \%$ of them use family planning method (TDHS, 2010). Use of family planning has shown to significantly reduce maternal mortality (UNFPA \& PATH 2008), since it minimizes the chances of getting unplanned pregnancy which increases risk of unsafe abortion (Rogo et al.,2006:

More than $94 \%$ of women attend antenatal care (ANC) in health facilities at least once but only 47\% deliver in these facilities (TDHS 1999, 2005; URT 2010). Even those delivering in health facilities not all receive skilled attendance at birth. Of the $53 \%$ of births that occur outside the health facilities $31 \%$ are attended by relatives, $19 \%$ by traditional births attendants (TBA) while $3 \%$ have no assistance at all (TDHS, 2005). This indicates that there are factors that impede these women delivering in the health facilities. It is now agreed that skilled attendance at delivery and timely access to quality EmOC when a complication occurs, are the best ways to avoid deaths and morbidities in women (Berer, 2007). The use of trained TBA to reduce maternal mortality has limited and often conflicting evidence (Greenwood et al., 1990; Daga, 1997). Some authors support to continue using trained TBAs in areas where home births are common, maternal and neonatal mortality remains high and the shift to skilled attendance at delivery is a distant reality (Sibley, 2002).

Low awareness of danger signs of obstetric complication may be one of the contributing factors for delay or not seeking care when a complication occur thus contributing to the high maternal mortality. Studies in Tanzania show that most women are not aware of danger signs of obstetric complications (Mpembeni et al., 2007; Pembe, 2009). A study conducted in Mtwara shows that proportional of women delivered with skilled care increases with increasing knowledge of pregnancy danger signs (Mpembeni et al., 2007). Various efforts have been done to increase women's awareness of danger signs of obstetric complication. Introduction of focused antenatal care (FANC), with emphasis on individual counselling on danger signs and other education messages including birth plan and emergency readiness $(\mathrm{MoH}, 2002)$ is expected to increase community awareness. Despite that effort of the introduction of FANC, less than half of the women receiving antenatal care are informed of danger signs of pregnancy complication (TDHS, 2005). A study in north western Tanzania revealed that knowledge of danger signs of obstetric complication and use of district hospitals by women with obstetric complications increases when there is sensitization and involvement of the community (Ahluwalia et al., 2003). It is not stated as to how women's knowledge was increased, although it was mentioned that Village Health Workers and TBAs were used in helping community to make decisions. In Guatemala, increase in awareness of danger signs of obstetric complication was observed through community and clinic based education. Radio messages were used as well as community educational sessions conducted through women groups (Perreira, 2002).

Like elsewhere in the world, caesarean section rates are increasing being reported Tanzania. At Muhimbili National Hospital (MNH), in Tanzania, an increase in the rate of caesarean section from $15.8 \%$ in 1999 to $31.8 \%$ in 2004 has been recorded. A study conducted at MNH in 2006 reported CSR of $29.5 \%$. Thirty percent of decision for emergency CS in the five most frequent indications are sub-optimal and may contain women in whom surgical interventions could be avoided (Mdegela, 2006). Repeat caesarean section has been reported as the second common indication for emergency caesarean section (Mdegela, 2006). Recently, in another study at MNH, $11 \%$ (365) of the women had one previous caesarean section. Almost half (48\%) of the women with one previous caesarean section had attended antenatal care in the dispensaries and health centres. A total of 278 women had the decision for repeat caesarean section made on admission whereby 180 (64.4\%) were for emergency caesarean section and 98 (35.6\%) were for elective caesarean section (Pembe \& Othman, 2010). This recent study indicates that a significant proportion of women delivering at MNH had one previous caesarean section (Muganyinzi et al., 
2008). The increase in the number of CS at referral hospitals has been explained to be attributed to lack of round-the-clock availability of comprehensive obstetric care services at some district hospitals, health centres and dispensaries (Nyamtema et al., 2008). This therefore, prompts the health facilities to refer pregnant women directly to referral hospitals (Pembe \& Othman, 2010). However, it is the fact that doctors and women have pressure of getting babies with good apgar scores should not be ignored (Pembe \& Othman, 2010).

Inadequate quality of health services provided by the health care system in Tanzania has been cited as among the reasons for maternal deaths in a study carried out in Dar es Salaam city by Urassa et al. (1995). Surprisingly, the majority of the deaths occurred among women who had contacted modern health care system and spent reasonable time receiving treatment.

The government budget allocation for health sector has increased from 13.45\% in 2006/7 to $13.87 \%$ in $2008 / 9$ which is close to Abuja target of $15 \%$ by 2015 . However budget allocated for maternal health has been inconsistent for a number of recent years. In 2006/7, 2007/8 and 2008/9 the budget for maternal health was $2.7 \%, 10.09 \%$ and $6.3 \%$, respectively (NAO, 2011). On the other hand, delivery of maternal health services is highly challenged by inadequate numbers of skilled health workers and still those available are unevenly distributed. In some health facilities particularly at lower levels in underserved areas, medical attendants, who are marginally skilled, are the ones providing services (MoHSW, 2008b). Human resource for health is critical such that in some regions such as Kagera, Shinyanga, Tabora and Kigoma have a shortage of more than twice the number of health worker per 10,000 populations (President PO-PSM, 2008). Lower levels health facilities are mostly stricken by shortage of health workers. Dispensaries and health centres have shortages of $65.6 \%$ and $71.6 \%$, respectively. The shortage of health workers has a major impact in maternal health particularly provision of skilled attendance during labour and emergency obstetric care (MoHSW, 2008a). The shortage of health workers is contributed by poor skills mix; inadequate incentives and salary packages; poor motivation; inadequate performance assessment and rewarding systems; poor retention of staff especially in remote and underserved areas and inadequate supportive supervision (Munga \& Maestad, 2009; Munga et al., 2009).

Monitoring progress towards achievement in maternal mortality reduction requires reliable data and good coverage of vital registration. However the health management information management system is inadequate, it is characterised by weaknesses in collection, untimely and unreliable data for decision making and planning (Franco et al., 2002; Mghamba et al., 2004). There are still un-integrated health interventions project which increases demand for more staff time, supervision and cost, since most of these interventions fulfils the donors preference as opposed to holistic approach to improve the health system, hence increase regional and rural -urban gap.

\section{Opportunities to reduce maternal death in Tanzania}

There are opportunities to reduce maternal deaths in Tanzania. Good coverage of ANC attendance of about $96 \%$ and around $90 \%$ of the population of people in Tanzania has an access to health facilities within $5 \mathrm{~km}$ from their home. Maternal and child health including antenatal, delivery, family planning services, malarial and anaemia control services including ITN are provided free of charge to pregnant women in all public facilities in Tanzania. Therefore pregnant women from low income families can access even emergence services at high level facilities.

Increasing public-private sectors collaboration among various implementers of maternal health services at National, Region and district level helps to increase health care services. Donors and development partners are injecting funds to the basket funding and district council budgets which allows flexibilities to address the felt need of the health facilities both at the national and district level. There is political will and Government leadership commitment in supporting efforts to improve maternal mortality reduction issues by ensuring there is good environment for implementation through provision of different guidelines and policies. 
The increasing number of health professional graduates and health institutions providing both pre-services and in-services are expected to solve the inadequate number of skilled delivery. Moreover, some of the training institutions have started offering short training courses in emergency obstetric care services for nurses/midwives and clinicians. Blood Transfusion Programme is expanding its services up to the district hospitals which increase availability of safe blood for emergency obstetric care.

\section{Conclusion and the Way Forward}

Maternal mortality ratio in Tanzania is unacceptably high and still very far from reaching the millennium development goals. Maternal health care services should focus on ensuring there is continuum of care through strengthening the health system and provision of good quality of health care in a well organized referral health system from community level to high facility levels. Addressing the rural-urban differences should be a priority in order to ensure EmOC services are available up to the peripheral health facility levels. It is important to ensure that health facilities are well equipped with required mix of skilled personnel, essential drugs and simple standard equipment with availability of reliable transport to attend emergency services in case there is a need for referral to high level facilities. Specific strategies should be in place to empower women, men and community members at large which are complemented with adequate health information for them to make informed decision of issues affecting health and family. The government budget allocation cannot meet the need of the health system; therefore there is a need for resource mobilization within the country, to fill in the gaps rather than depending largely on donor funding support which are not sustainable. Government support and leadership commitment, strong public-private partnership in health service delivery, sharing of best practices experiences, and an organized monitoring and evaluation system backed up with a well functioning health information system can help to facilitate improvement of delivery of quality maternal health care services.

To mount an effective maternal health effort aimed at reducing maternal mortality, multiple levels of programme and policies need to be in place and functioning. In addition, linkages, from the communities, local dispensaries and health centres to first referral hospitals that are adequately equipped, need to be developed and sustained (WHO 1994; Alisjahbana et al., 1995; Goodburn, 2001; Ahluwalia et al., 2003). In early $20^{\text {th }}$ century, developed countries decreased their maternal mortality through increasing professional midwifery care at delivery and access to effective hospital treatments. When quality care in first line and referral facilities are combined then the maternal mortality can be reduced very fast as occurred in developed countries (Van Lerberghe, 2001).

An intervention programme that was implemented in Kigoma Region from $1987-1991$ which involved internal training of health care providers, with regular audit-oriented meeting, improving equipment and availability of drugs and supplies resulted into remarkable improvement of quality of obstetric care as well as obstetric outcome that included reduction of maternal and perinatal mortalities and morbidities overtime (Mbaruku, 1995). This interventional programme was not scaled up or adapted to other districts, therefore it is difficult to be evaluated and generalized as the best way to reduce maternal mortality and morbidity in the country. An integrated horizontal approach to maternal health need to be advocated in the country. Already, in a study in northern Tanzania, an integrated and comprehensive hospital/community based health programme aimed at reducing maternal and child mortality and morbidity has been successfully tested (Evjen-Olsen et al., 2009).

In conclusion, the direct causes and problems associated with maternal death have already been identified and solutions have been proposed. However, the main issue is how to apply the solutions taking into account the socio-cultural, political and economic realities and inherent constraints. The majority of women in Tanzania still deliver at home with no skilled attendant, but even with those who deliver in the health care facilities, the quality of care is 
questionable. Scaling up of effective initiatives aimed at reducing maternal death is the key to achieving Millennium Development Goals. However, insufficient resources, and other associated socio-economic and cultural factors preventing an effective scale-up of the interventions are major causes for concern. This review therefore recommends the following to be done:

\section{Strengthening the health system}

Upgrading health facilities in terms of infrastructures including construction of theatres and maternity waiting homes in rural areas which are well equipped with standard equipments is recommended. It is important to ensure consistency provision of essential drugs and supplies in all health care facilities. In addition high priority should be given to EmOC services facility in hard to reach rural areas by ensuring there is a good referral system from community level to high level facilities.

Upgrading health workers skills especially staff of lower cadre who are the most common service providers at lower level facilities in the rural areas. This will involve supporting more training to assistant medical officers and clinical officers to provide EmOC services in rural areas were medical doctors are unavailable. There is need to ensure skilled delivery especially in lower level facilities in rural areas by providing adequate supplies. Evenly distribution of skilled health workers among districts and provision of motivation packages to attract and retain health worker to stay and continue working in rural areas is equally important.

There is need to strengthen the integration of various health projects and programmes for easy management, monitoring, supervision and efficient use of available resources since discrete projects have less impact. Equally important, there is need to strengthening the routine Health Information System to provide process indicators to monitor progress towards reduction of maternal mortality. In addition, the strengthening of maternal reviews at all levels and sharing of experiences across districts and regions in order to make early decisions for planning to address specific needs is crucial. Outreach health education services to communities should be strengthened. This will ensure communities understand maternal and reproductive health care services, and therefore increase demand of services such as family planning. There is need to encourage health facilities deliveries, attending postnatal checkups and adherence to treatment and prevention programmes such malaria control programmes, PMTCT and immunization among mothers.

\section{Women empowerment and community participation}

There is need for the government to support socio-economic women empowerment programmes so that women can take decision affecting their health and the family at large including decision to access to quality health care. This can be done by proving women with education, entrepreneur skills and facilitate access to financial capital and assistance for self-reliance activities. Community participation and involvement in health care services should be encouraged and strengthened. This can be done by capacitating village health committees to play their role to monitoring health indicators in their communities and demand for government and other health actor's support towards health issues facing the particular community. Advocacy should focus to male partner involvement in reproductive health services. This can be done by designing strategies for educating, sensitizing and encouraging male partners participation since they are both financial and decision makers and hence determinants of the family health care seeking behaviour.

\section{Strengthening operation research}

Operations research addressing maternal health challenges for informed decision making in policy formulation and health sector planning should be enhanced. The government and development partners should be ready to support health research priorities in the context of maternal health and not otherwise. 


\section{References}

AbouZahr, C. (2003) Safe Motherhood: A Brief History of the Global Movement 1947-2002. British Medical Bulletin 67, 13-25.

AbouZahr, C., Wardlaw, T., Stanton, C. and Hill, K. (1995) Maternal mortality. World Health Statistics Quarterly 49, 77-87.

Ahluwalia, I.B., Schmid, T., Kouletio, M. and Kanenda, A. (2003) An evaluation of a communitybased approach to safe motherhood in north-western Tanzania. International Journal of Gynecology and Obstetrics 82, 231240.

Alisjahbana, A., Williams, C., Dharmayanti, R., Hermawan, D., Kwast, B.E. \& Koblinsky, M. (1995) An integrated village maternity service to improve referral patterns in a rural area in WestJava. International Journal of Gynecology and Obstetrics 48 (Suppl), S83-BS94.

Berer, M. (2007) Maternal mortality and Morbidity: Is Pregnancy Getting Safer for Women? Editorial. Reproductive Health Matters 15, 6-16.

Campbell, O.M. (2006) Strategies for reducing maternal mortality: getting on with what works. www.ncbi.nlm.nih.gov/pubmed/17027735.

Commonwealth Secretariat (2008) Maternal Morbidity: an overview and a Tanzania case study. Marlborough House, London. 8 October 2008.

Evjen-Olsen, B., Olsen, Ø.E. \& Kvåle, G. (2009) Achieving progress in maternal and neonatal health through integrated and comprehensive healthcare services-experiences from a programme in northern Tanzania. International Journal for Equity in Health 8:27.

FHI (2007) Safe Motherhood: A Review 1987-2005. Family Health International 4,78-82.

Franco, L., Fields, R., Mmbuji, P.K.L., Posner, S., Mboera, L.E.G., Jimmerson, A., Senkoro, K.P., Rumisha, S.F., Shayo, E.H. \& Mwami, J.A. (2003) Situation Analysis of Infectious Disease Surveillance in two Districts in Tanzania, 2002. Working Paper, Bethesda, MD: The Partners for Health Reformsplus Project, Abt Associates Inc. <http://www.phrplus.org/Pubs/WPo04_fin.pdf.

Greenwood, A.M., Bradley, A.K., Byass, P., Greenwood, B.M., Snow, R.W., Bennett, S. \& HatibN'Jie, A.B. (1990) Evaluation of a primary health care program in the Gambia. I. The impact of trained traditional attendants on the outcome of pregnancy. Journal of Tropical Medicine and Hygiene 93, 58-66.

Guttmacher, I.O. (2009) Abortion Worldwide: A decade of uneven progress: Report http://www.guttmacher.org/pubs/Abortion-Worldwide.pdf

$\mathrm{FCl}$ (2011) Safe motherhood international; A review. Family Care International.

Ipas (2009) Misoprostol and Medical abortion in Africa (MISOATR-E09).

Koblinky, M.A. (2003) Reducing Maternal Mortality: Learning from Bolivia, China, Egypt, Honduras, Indonesia, Jamaica and Zimbabwe. The World Bank, Human Development Network.

Mandara, M.P. \& Kaisi, M. (1991) Maternal mortality. In: Health and Diseases in Tanzania. G.M.P. Mwaluko, W. Kilama, M.P. Mandara, C.N.L. Macpherson (eds).

Massawe, S.N., Urassa, E.N., Mmari, M., Ronquist, G., Lindmark, G. \& Nystrom, L. (1999) The complexity of pregnancy anaemia in Dar-es-Salaam. Gynaecologic and Obstetric Investigation 47, 76-82.

Mbaruku, G. \& Bergstron, S. (1995) Reducing Maternal mortality in Kigoma, Tanzania. Health Policy and Planning 10, 71-78.

Mdegela, M. (2006) Emergency Caesarean Section: Evaluation of Indications and Pregnancy Outcome at Muhimbili National Hospital. Dissertation of Master of Medicine (Obstetrics and Gynaecology), University of Dar es Salaam.

Mghamba, J.M., Mboera, L.E.G., Krekamoo, W., Senkoro, K.P., Rumisha, S.F., Shayo, E.H. \& Mmbuji, P. (2004) Challenges of implementing Integrated Disease Surveillance and Response strategy using the current Health Management Information System in Tanzania. Tanzania Health Research Buletin 6, 57-63. 
MoH (2000) National Package of Essential Reproductive and Child Health Interventions. Ministry of Health, Dar es Salaam, Tanzania.

MoH (2002) Focused antenatal care, malaria and syphilis in pregnancy: Orientation package for service providers. Ministry of Health, Dar es Salaam, Tanzania.

MoH (2003) National Policy Guidelines for Reproductive and Child Health Services. Ministry of Health, Dar es Salaam, Tanzania.

MoH (2004) Reproductive and Child health Strategy. Ministry of Health, Dar es Salaam, Tanzania.

MoHSW (2006) Challenges on Adolescent Health and Development an Advocacy Guide. Ministry of Health and Social Welfare, Dar es Salaam, Tanzania.

MoHSW (2007) Primary Health Care Services Development Programme 2007-2017. Ministry of Health and Social Welfare, Dar es Salaam, Tanzania.

MoHSW (2008a) The National Road Map Strategic Plan to Accelerate Reduction of Maternal, Newborn and Child Deaths in Tanzania 2008-2015 - One Plan. Ministry of Health and Social Welfare, Dar es Salaam, Tanzania.

MoHSW (2008b) Health Sector Performance profile Report: Mainland Tanzania July 2006-June 2007. Ministry of Health and Social Welfare, Dar es Salaam, Tanzania

MoHSW (2009) Situation Analysis of Newborn Health in Tanzania: Current situation, Existing Plan and Strategies next Step for Newborn Health. Ministry of Health and Social Welfare, Dar es Salaam, Tanzania.

Mpembeni, R.N.M., Killewo, J.Z., Leshabari, M.T., Massawe, S.N., Jahn, A., Mushi, D. \& Mwakipa, H. (2007) Use pattern of maternal health services and determinants of skilled care during delivery in southern Tanzania: Implications for achievement of MDG-5 targets. BMC Pregnancy and Childbirth 7:29

Mtei, G., Mulligan, J., Ally, M., Palmer, N. \& Mills, A. (2007) An assessment of Health Financing Systems in Tanzania. Report on Shield Work Package I.

Muganyizi, P., Kidanto, H., Kazaura, M. \& Massawe, S. (2008) Caesarean section: trends and associated factors in Tanzania. African Journal of Midwifery and Women's Health 2, 65-68.

Munga, M.A. \& Maestad, O. (2009) Measuring inequities in the distribution of health workers: the case of Tanzania. Human Resources for Health 7:4.

Munga, M.A., Songstad, N.G., Blystad, A. \& Maestad, O. (2009) The decentralisation-centralisation dilemma: recruitment and distribution of health workers in remote districts of Tanzania. BMC International Health and Human Right 9: 9.

NAO (2011) A Performance Audit on the Monitoring, Evaluation and Budget Allocation for Maternal Health Care Activities in Tanzania.

Nyamtema, A.S., Urassa, D.P., Massawe, S., Massawe, A., Mtasiwa, D., Lindmark, G. \& van Roosmalen, J. (2008) Dar es Salaam perinatal care study: needs assessment for quality of care. East African Journal of Public Health 5, 17-21.

Pembe, A.B. \& Othman, M.K. (2010) Pregnancy outcome after one previous caesarean section at a tertiary university teaching hospital in Tanzania. Tanzania Journal of Health Research 12 (3).

Perreira, K., Bailey, P., Bocaleti, E., Hurtado, E., Villagran, S. \& Matute, J. (2002) Increasing Awareness of Danger signs through community- and Clinic based education in Guatemala. Maternal and Child Health Journal 6, 19-28.

Rogo, K.O., Ouch, J. \& Mwalali, P. (2006) Maternal Mortality: Disease and Mortality in Sub-Saharan Africa. $\quad 2^{\text {nd }} \quad$ edition. World Bank, Washington DC. http://www.ncbi.nlm.nih.gov/pubmed/21290649

Sibley, L. \& Sipe, T. (2002) Traditional birth attendant training effectiveness: a meta-analysis. Unpublished technical report. Academy for Educational Development /SARA Project, Washington, D.C.2002.

Sines, E., Tinker, A. \& Ruben, J. (2006) The Maternal-Newborn-Child Health Continuum of Care: A collection Efforts to Save Lives: Save the Children. Population Reference Bureau.

Tanzania Development Vision 2025. http://.tanzania.go.tz/vision.htm visited 17/01/07 
TDHS (1999) Tanzania Demographic and Health Survey 1999. National Bureau of Statistics, Dar es Salaam Tanzania and ORC Macro.

TDHS (2005) Tanzania Demographic and Health Survey 2004/2005. National Bureau of Statistics, Dar es Salaam, Tanzania and ORC Macro.

TDHS (2010) Tanzania Demographic Health Survey, 2010. National Bureau of Statistics, Dar es Salaam, Tanzania and ORC Macro.

UN (2011) The Millennium Development Goals Report. http://www.un.org/millenneumgoals/

UNFPA \& PATH (2008) Reducing unmet need for family planning: Evidence based strategies and approaches for addressing. UNFPA and PATH

UNICEF (2009) The State of The World Children 2009: Maternal and Newborn Health.

Urassa, E., Lindmark, G. \& Nystrom, L. (1995) Maternal mortality in Dar es Salaam, Tanzania: Socioeconomics, obstetric history and case accessibility of health care factors. African Journal of Health Sciences 2, 242-249.

URT (2005) National Strategy for Growth and Reduction of Poverty (NSGRP). Vice Presidents Office, United Republic of Tanzania, Dar es Salaam.

URT (2006) National Population Policy. United Republic of Tanzania.

URT (2009) Speech by Hon. Mizengo P. Pinda, Prime Minister of the United Republic of Tanzania during the opening ceremony on Best Practices for Maternal Survival in Sub-Saharan Africa at Tanzania Training Centre for International Health , Ifakara, 19th October 2009.

URT (2010) National Strategy for Growth and Reduction of Poverty (NSGRP II). Ministry of Finance and Economic Affairs, United Republic of Tanzania 2010.

URT (2011) Health Impact of the Scale-Up to Fight HIV, Tuberculosis and Malaria In Tanzania: District Comprehensive Assessment of the Global Fund Five Year Impact Evaluation. United Republic of Tanzania, Dar es Salaam.

USAID (2008) MCH Program Description Tanzania. United States Agency for International Development.

Van Lerberghe \& De Brouwere, V. (2001) Reducing maternal mortality in the context of poverty. In Safe motherhood strategies: A review of the evidence. Studies in Health Services Organization and Policy 17. ITG Press; 2001.

VSI-IHI (2011) Bixby Centre for Population Health and Sustainability and Berky Collaborations. Prevention of postpartum haemorrhage in home births: Misoprosotol during Antenatal care visits in Tanzania.

Wagstaf, A. \& Claeson, M. (2004) The Millennium Development Goals for Health: Rising to the Challenges. World Bank, Washington DC.

Waldijk, K. (1994) Surgeons show success in early fistula repairs. Safe Motherhood Newsletter, Issue 14, March-June 1994.

WB (2011) Maternal Death Audit as a Tool Reducing Maternal Mortality. World Bank, Washington DC.

WHO (1978) Declaration of Alma-Ata International Conference on Primary Health Care, Alma-Ata, USSR, 6-12 September 1978.

WHO (1993) International Statistical Classification of Diseases and Health Related Problems. Volume 2. Geneva

WHO (1994) Mother-Baby Package: Implementing Safe Motherhood in Countries. Practical Guide: Maternal Health and Safe Motherhood Programme. Division of Family Health, World Health Organization

WHO (2004) Beyond the Numbers Reviewing Maternal Deaths and Complications to Make Pregnancy Safer. World Health Organization, Geneva, Switzerland.

WHO (2005) Reducing Maternal Deaths: The Challenge of the New Millennium in the African Region. World Health Organization, Geneva, Switzerland.

WHO/UNICEF/UNPF/ World Bank (2005) Maternal Mortality in 2005.. World Health Organization, Geneva. 
WLF (2011) Improving Maternal Health in Tanzania. World Lung Foundation. http://www.worldlungfoundation.org/ht/d/sp/i/14877/pid/14877. 